\title{
Software libre en las bibliotecas de la UPC
}

\author{
Por Javier Clavero, Eulàlia Formentí y Toni Prieto
}

Resumen: Se exponen los proyectos y experiencias de implantación y uso de software libre en las bibliotecas de la Universitat Politècnica de Catalunya (UPC). El software libre es un movimiento que tiene cada vez mayor importancia, sobre todo en ámbitos universitarios. El uso de estándares potencia la interoperabilidad entre sistemas, lo que redunda en una mayor difusión de los datos. Las bibliotecas de la UPC están creando depósitos institucionales para dar acceso a la producción docente y de investigación a través de plataformas de software libre como DSpace. Las bibliotecas de la

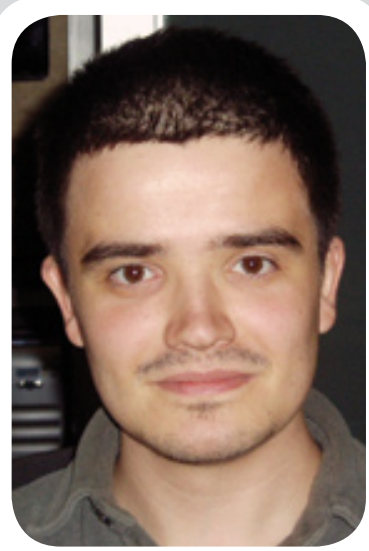

Javier Clavero, licenciado en ingeniería informática por la Facultad de Informática de Barcelona. Es técnico IC de la Biblioteca Rector Gabriel Ferraté del campus nord de la Universitat Politècnica de Catalunya.

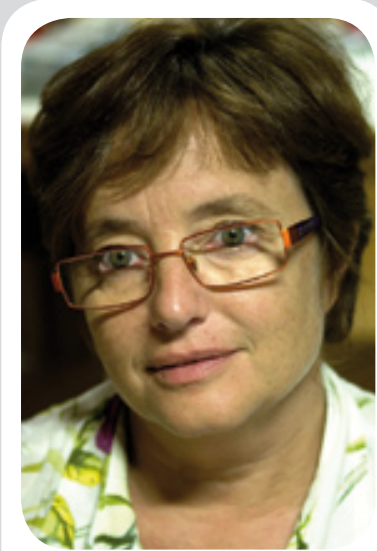

Eulàlia Formentí es licenciada en informática por la Universitat Politècnica de Catalunya en 1985 y responsable de la Càtedra de programari lliure de la UPC.

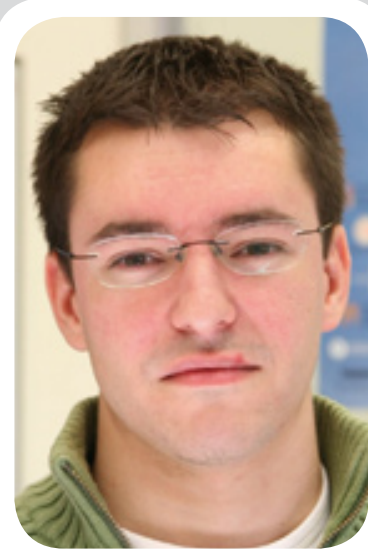

Toni Prieto, licenciado en ingeniería informática por la Facultad de Informática de Barcelona, es técnico IC del Servicio de Bibliotecas y Documentación de la Universitat Politècnica de Catalunya.

UPC seguirán trabajando en proyectos de software libre y promoviendo el uso del mismo entre sus usuarios y entre la comunidad universitaria.

Palabras clave: Software libre, DSpace, Biblioteca, Universidad, Depósito, Linux, Interoperabilidad, Estándares.

\section{Title: Free software at the UPC libraries}

\begin{abstract}
We reviewed projects and outcomes in the implementation and use of free software in the Technical University of Catalonia (UPC) libraries. Free software is a growing movement with steadily increasing significance, especially in university environments. The use of standards improves the possibility of integration with other systems and enhances the efficient management of library data. At the moment UPC libraries are developing their institutional repositories, using open source software like DSpace to disseminate the institution's teaching and research activities. The UPC libraries will continue to implement this cost effective software and promote its use among library users and the university community.
\end{abstract}

Keywords: Free software, DSpace, Library, University, Repository, Linux, Interoperability, standards.

Clavero, Javier; Formentí, Eulalia; Prieto, Toni. “Software libre en las bibliotecas de la UPC”. En: El profesional de la información, 2008, enero-febrero, v. 17, n. 1, pp. 56-63.

DOI: 10.3145/epi.2008.ene.06

\section{El software libre}

FORMA PARTE DE UNA IDEOLOGÍA más universal conocida como "conocimiento libre". La idea fundamental de esta filosofía es que el conocimiento no puede ser un bien comerciable $y$, por tanto, la figura de los derechos de autor tiene un impacto negativo sobre la generación y difusión del conocimiento y del progreso.

La Wikipedia define así el conocimiento libre1: "Hasta hace pocas décadas el conocimiento era patrimonio de la humanidad, y existía libertad de uso y acceso al mismo. Con la aparición de límites artificiales como las patentes y los derechos de autor, entre otros (mal denominados en conjunto propiedad intelectual), el conocimiento perdió esta característica. Mientras que el avance de la tecnología por lograr una sociedad digitalizada y conectada brinda al conocimiento humano nuevas posibilidades de crecimiento, estos límites artificiales están restringiendo la posibilidad de aprovechar este potencial".
Internet pone de manifiesto este problema: la tecnología nos permite difundir el conocimiento con una facilidad y velocidad jamás imaginadas, pero la Ley de propiedad intelectual $^{2}(L P I)$ pone cortapisas a esta difusión. Tenemos que revisar el marco legal de la propiedad intelectual para adaptarlo a las necesidades actuales y permitir que el conocimiento sea patrimonio de la humanidad.

El contexto legal que ampara el software es también la LPI: los 
programas legalmente son obras intelectuales, al igual que un libro, un cuadro o una fotografía. Las licencias de software hacen las veces de contrato entre el desarrollador o el distribuidor del mismo y el usuario; en ellas se establecen las condiciones de uso y los derechos de autor que se transfieren o restringen al usuario.

Richard Stallman, creador del proyecto $G N U^{3}$ y máximo impulsor del concepto del software libre, lo definió como aquel que otorga al usuario los siguientes derechos para:

- Ejecutarlo para cualquier propósito.

- Estudiar cómo funciona y adaptarlo a sus necesidades. Es indispensable el acceso al código fuente.

- Redistribuirlo.

- Modificar el programa y distribuirlo con las modificaciones realizadas. En este caso también es necesario el acceso al código fuente.

Las licencias de software libre garantizan estos derechos a los usuarios. La Free Software Foundation ${ }^{4}$ redactó la primera licencia de software libre, y la más utilizada, la General Public License $(G P L)^{5}$.

El movimiento del software libre se organiza en comunidades de desarrollo organizadas por proyectos, cada una generalmente con un líder, los desarrolladores y los colaboradores. El líder tiene que ser una persona muy activa, encargada de las relaciones personales con el resto de colaboradores, de los temas relacionados con nuevas versiones y de la promoción (documentación, sesiones informativas, software parties, sprint sessions, etc.). La organización de las comunidades es poco jerárquica y el reconocimiento entre sus miembros es por meritocracia. Las personas que forman una comunidad están altamente motivadas, técnicamente prepara- das y fuertemente comprometidas con el objetivo a conseguir.

\section{Las universidades y el software libre}

Las universidades nacionales e internacionales participan activamente en el debate del conocimiento libre y en particular, del software libre. En un principio, todo se originó persona a persona: investigadores, personal de administración y servicios, y estudiantes. La mayoría del software utilizado en las universidades para los programas de investigación y docencia es libre y muchos de estos proyectos nacen en grupos de investigación, o con investigadores de universidades que participan, a título individual o del grupo. La incorporación de las instituciones a este movimiento es más reciente.

Los programas que se realizan para la investigación forman parte de la misma y su código es utilizado por distintos grupos sin licencias que regulen su utilización. Sólo son conocidos por los grupos afines.

Las universidades nacionales han empezado a crear oficinas para impulsar y dinamizar el software libre. En el proyecto IRIS-libre ${ }^{6} \mathrm{de}$ RedIris $^{7}$ se recogen las distintas organizaciones de cada una de las universidades con sus proyectos.

\section{La UPC y el software libre}

Como universidad tecnológica, la $U P C$ es una entidad consumidora, productora y formadora de software: el movimiento del software libre está presente en cada uno de estos ámbitos. Como en el resto de las universidades, el uso y desarrollo de software libre es común en cada una de las actividades a realizar, pero también es un movimiento ligado a las personas y a los grupos de investigación.

En 2004 la UPC creó la Càtedra de programari lliure (CPL) para impulsar y dinamizar esta tendencia. La CPL está implementando el Pla estratègic del programari lliure, donde se recoge la necesidad de introducir la filosofía del conocimiento libre en cada uno de las áreas de la UPC y las líneas estratégicas que deben impulsarse.

Las bibliotecas de la UPC han adquirido el compromiso de trabajar para utilizarlo cada vez más, tanto para aplicaciones y plataformas web como en los ordenadores que se ponen a disposición de los usuarios en las bibliotecas.

\section{“En 2004, la UPC creó la Càtedra de Programari Lliure (CPL) para impulsar y dinamizar el uso del software libre"}

\section{El software libre en las aplicaciones web de las BUPC}

En este punto se incluye tanto la producción de nuevas aplicaciones como la progresiva migración de otras ya en explotación, que fueron creadas mediante software propietario, en su mayoría de $\mathrm{Mi}$ crosoft. Por otro lado, la proliferación de diversas aplicaciones web en software libre muy completas y fáciles de implantar es otra motivación más en la realización de nuevos proyectos.

\subsection{Implementación con soft- ware libre existente}

Puede hallarse un gran número de soluciones muy completas, realmente útiles en el trabajo diario de una biblioteca universitaria. Un ejemplo son los wikis, muy prácticos para el trabajo en grupo del personal de las bibliotecas, o los blogs, excelentes como herramienta de comunicación e interacción. En el caso de las $B U P C$, se eligió $M e$ - 


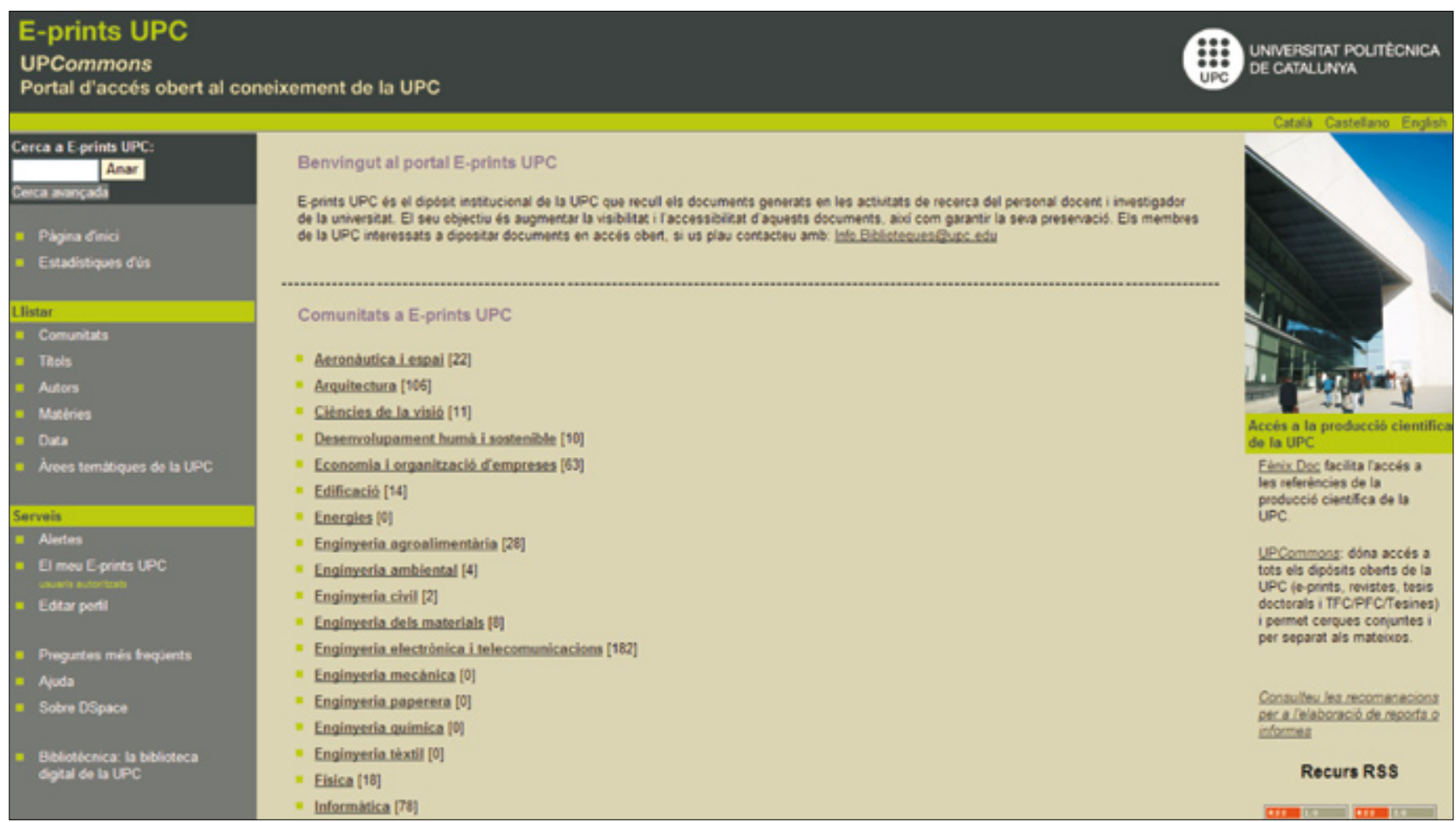

Portal E-prints UPC

diaWiki ${ }^{8}$ para la creación de wikis y Wordpress ${ }^{9}$ para los blogs, que se instalan rápidamente sin apenas hacer modificaciones. Prácticamente sólo se tuvieron que configurar extensiones ya existentes, por ejemplo para integrar la validación de usuarios con el servidor $L D A P^{10}$ de la $U P C$, y personalizar algunos aspectos de la aplicación. Pero es $D S$ pace $^{11}$ el programa con el que se ha tenido una mayor implicación.

\subsection{DSpace}

Es una plataforma en código abierto para la implementación de depósitos documentales, desarrollada por las bibliotecas del Massachusetts Institute of Technology (MIT) y la empresa Hewlett-Pac$k a r d$, y para la cual han creado recientemente una compañía sin ánimo de lucro destinada a liderar su evolución y garantizar su futuro.

A principios de 2004 se creó un grupo de trabajo desde el Consorcio de Bibliotecas Universitarias Catalanas (CBUC) para acordar la selección de un programa en código abierto para los depósitos documentales de las universidades cata- lanas, que culminó con la elección de DSpace. A partir de entonces, tanto el $C B U C$ como varias universidades catalanas han iniciado sus depósitos mediante esta plataforma. En las BUPC se dispone de tres instalaciones para almacenar, diseminar y preservar los materiales producidos en la universidad. Es el caso de E-prints $U P C^{12}$, que almacena los trabajos producidos por los investigadores de la institución, y el depósito Revistes $i U P C^{13}$, que incorpora las revistas y documentación de congresos realizados en la universidad. Ambos se crearon desde cero, ya que anteriormente no existía ninguna aplicación que realizara sus funciones. En cambio, el tercer depósito, Treballs acadèmics $U P C^{14}$, es el resultado de la migración del contenido de un sistema en $A S P$ ya en explotación, donde se alojaban los trabajos académicos de fin de carrera de los estudiantes de la $U P C$.

Se está trabajando en la migración hacia DSpace de otro depósito, la Videoteca de la UPC, que inicialmente también se hizo con Microsoft y que alberga vídeos de confe-

\section{"Las bibliotecas de la UPC disponen de tres instalaciones de DSpace para almacenar, diseminar y preservar los materiales producidos en la universidad.}

rencias, clases, reuniones, etc., de la comunidad universitaria. Se pretende incorporar los documentos en formato Flash e integrar en la pantalla de datos de cada vídeo un visor para su reproducción. A pesar de no ser un formato libre, se ha escogido Flash dado que puede considerarse un estándar de vídeo en internet, ya que es uno de los más usados, sobre todo últimamente, gracias al impulso dado por sitios tan populares como YouTube. Por último, el portal UPCommons ${ }^{15}$, que es el encargado de dar acceso a todos estos depósitos y al resto de los gestionados por las $B U P C$ y responsable de ofrecer un acceso unificado a sus contenidos, es también DSpace. 


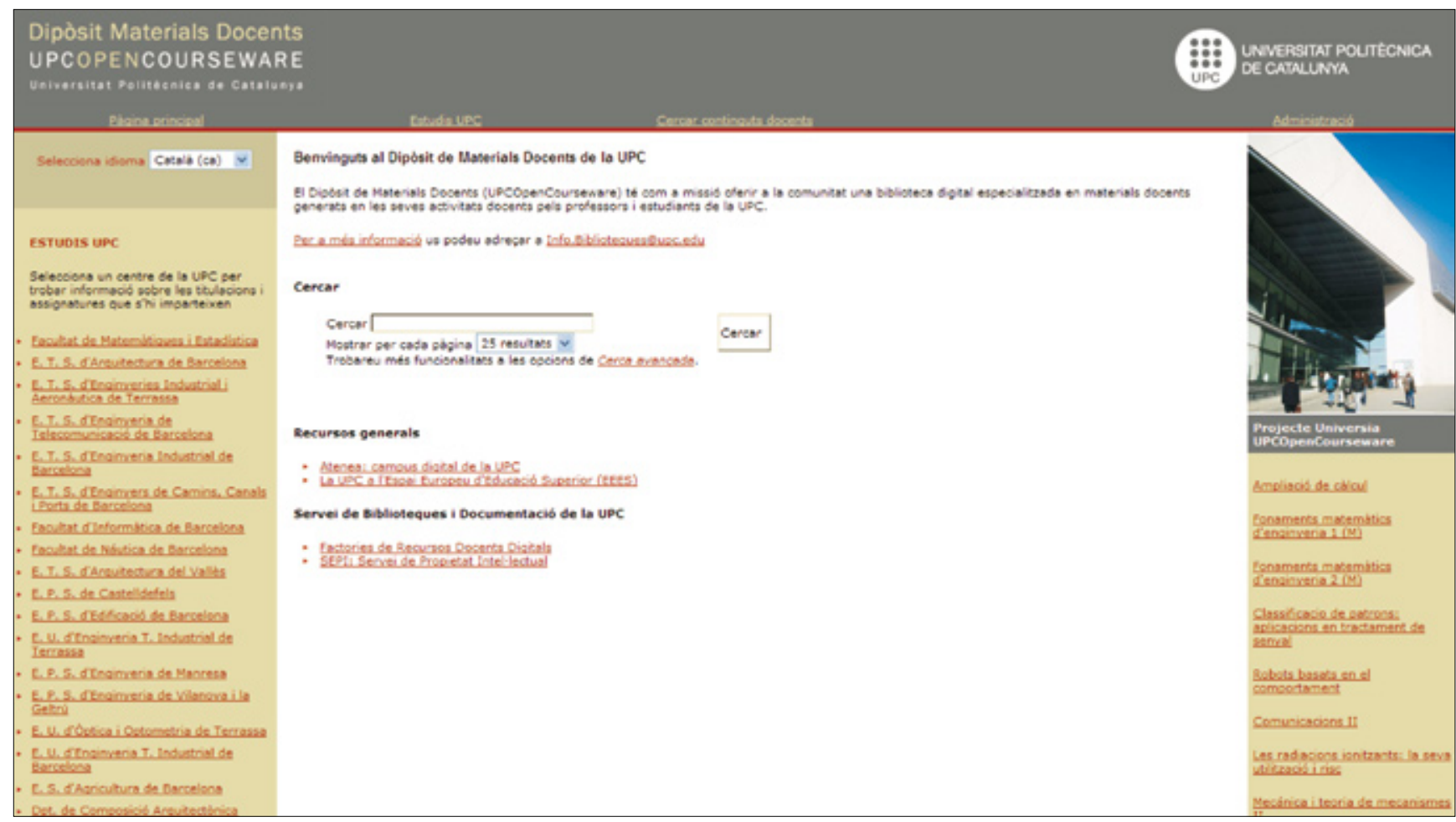

Dipòsit de Materials Docents UPC

Durante la realización de todos estos depósitos se han personalizado y modificado partes del software para adaptarlo a las necesidades de las bibliotecas. Estas innovaciones han sido tanto pequeños programas propios como instalaciones de parches disponibles en la web para solucionar fallos o incluir nuevas funciones. Se ha procurado que los cambios realizados sean mínimos, con el fin de que la futura actualización a las nuevas versiones, que a menudo ya incluyen las mejoras requeridas por los usuarios, sea lo más fácil posible.

El hecho de pertenecer a una gran comunidad de usuarios tiene la ventaja de que muchas de las necesidades y los problemas que surgen durante la puesta en marcha ya se hayan planteado y solucionado en otras instituciones. En este sentido, han sido muy útiles las herramientas que ofrece la comunidad de DSpace para la comunicación entre sus miembros, como las listas de distribución o el wiki. Además, en estas listas de distribución, especialmente en la destinada a dudas en el desarrollo técnico, los máxi- mos responsables de los cambios que se establecen en la plataforma están informando y discutiendo continuamente las decisiones tomadas, haciendo que su evolución sea muy abierta a la participación del resto de la comunidad.

\subsection{GUDE}

Tras observar que un gran número de universidades españolas tenían proyectos de implementación de depósitos institucionales mediante DSpace, se decidió impulsar la creación del Grupo de Usuarios de DSpace de España $(G U D E)^{16}$. Éste nació con el objetivo de compartir, colaborar en las mejoras, participar en las comunidades mun-

\section{"Dado el gran número de universidades españolas con proyectos de depósitos mediante DSpace, se decidió impulsar la creación del Grupo de Usuarios de DSpace de España"}

diales DSpace y organizar workshops de usuarios a escala española. Como canales de comunicación se dispone de una lista de distribución y un wiki donde se localizan las instalaciones y proyectos españoles, directorios, recolectores y otros.

Fruto del trabajo de varios miembros del grupo, se han traducido al castellano las nuevas versiones de las dos interfaces de usuario ofrecidas, así como algunos documentos de ayuda. En la lista de distribución, activa desde octubre del 2006, se comparten tanto dudas técnicas como otras de carácter más funcional, además de noticias y novedades.

\subsection{Desarrollos propios}

En algunas ocasiones se ha optado por hacer desarrollos propios, al no disponer de software que se ajustara a las necesidades requeridas. En estos casos se ha utilizado $\mathrm{PHP}^{17}$ como lenguaje de programación y el gestor de base de datos $M y S Q L^{18}$.

El ejemplo más significativo es el Dipòsit de Materials Docents ${ }^{19}$, que recopila y da acceso a los mate- 


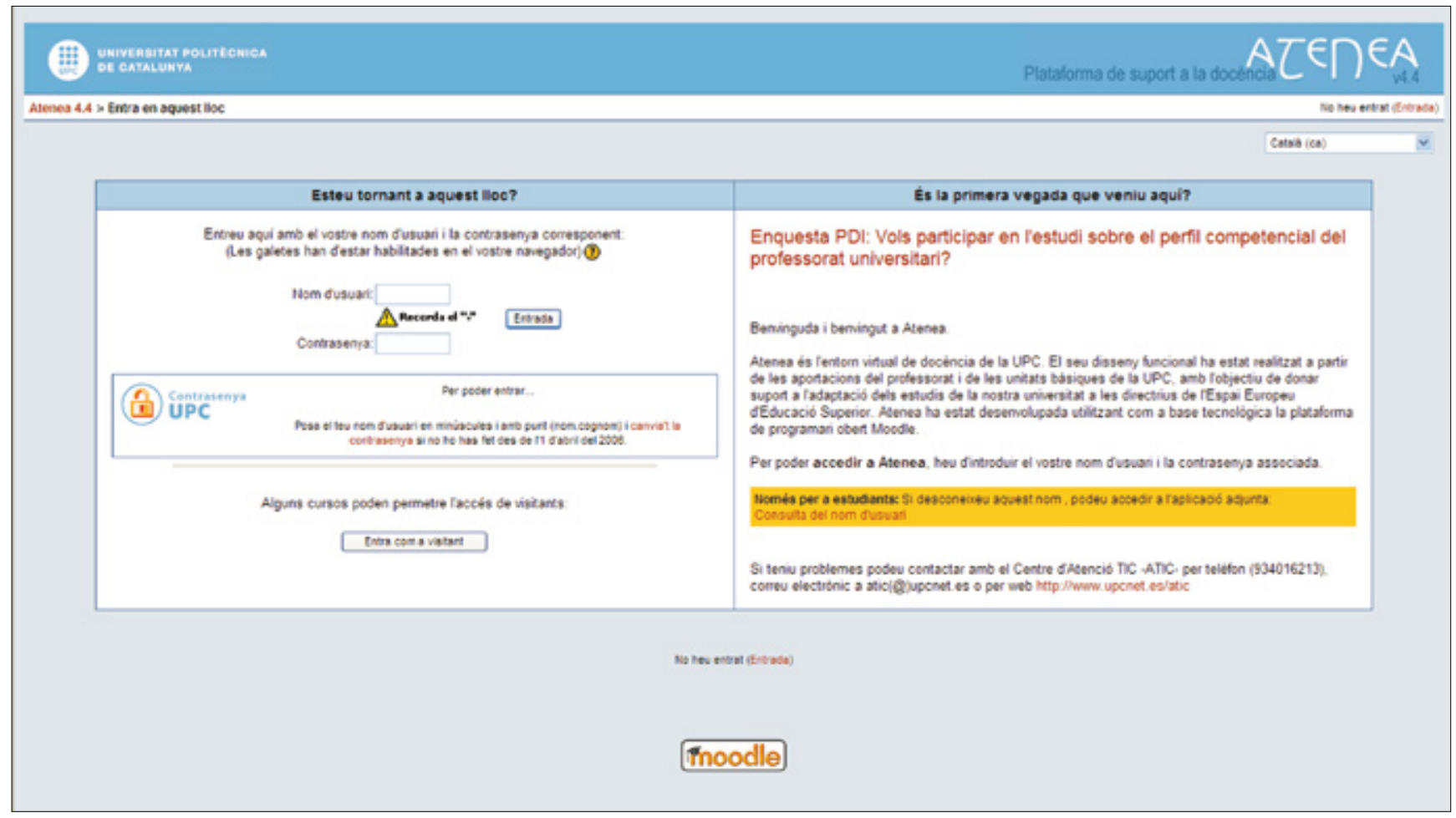

Atenea: el campus virtual de la UPC

riales de las asignaturas producidos por profesores y alumnos de la universidad en su actividad docente. Realiza y amplía las funciones que llevaba a cabo otro producto basado en software propietario, al que ha sustituido, y fue inicialmente creado como parte de un proyecto de fin de carrera de una estudiante de informática. Está formado internamente por tres partes separadas: el portal, donde se puede acceder a los materiales disponibles de las asignaturas mediante búsquedas; el depósito, donde se da entrada a los documentos y sus metadatos, y el gestor, en el que se listan y gestionan los materiales que se muestran en cada una de las asignaturas cursadas en la $U P C$.

Aunque inicialmente se consideró la opción de utilizar también DSpace, sobre todo para realizar las funciones de la parte de depósito, finalmente se desechó por dos razones: por un lado, no permitía la gestión de objetos compuestos hasta el nivel que se necesitaba y por otro, el sistema de circuitos de validación de metadatos no se ajustaba a las necesidades requeridas.
4.5. Interoperabilidad y estándares abiertos

Uno de los aspectos más destacables del Dipòsit de Materials Docents es su integración a distintos niveles con tres aplicaciones de la universidad:

- Atenea: el campus virtual de la $U P C^{20}$. A través de una pasarela de autenticación se permite introducir contenidos en su depósito y referenciarlos de manera transparente para el usuario.

- Prisma: el sistema de gestión académica. Fuente de datos para la obtención de las asignaturas con las que trabaja el gestor de contenidos.

- Gauss: sistema para la gestión e identificación de usuarios de la UPC desde donde se obtienen archivos para la actualización de privilegios de los profesores y se controla su autenticación a través del protocolo $L D A P$.

La utilización de software libre por otras entidades de la universidad ha facilitado, sin duda, esta integración. Un ejemplo claro es Atenea, que se migró hace unos años a la plataforma Moodle ${ }^{21}$.
En este aspecto juega también un papel fundamental el uso de estándares abiertos, muy ligados al concepto de software libre ya que, entre otras cosas, exigen la existencia de alguna implementación en abierto. Representan la herramienta más adecuada para la interoperabilidad de sistemas, ya sean aplicaciones de la propia institución o externas. El Dipòsit de Materials Docents sirve de ejemplo, ya que utiliza el protocolo estándar $S O A P^{22}$ para la comunicación entre las diferentes partes que lo forman (el depósito, el gestor y el portal) con el fin de que sean independientes y pueda reemplazarse alguna si es necesario sin tener que cambiar el resto.

Otro caso es la comunicación entre el depósito E-prints UPC y la aplicación Fénix, que gestiona la actividad académica del personal investigador de la universidad. Aquí, Fénix recupera e incorpora los metadatos de los materiales incluidos en el repositorio, tales como artículos, comunicaciones de congresos, etc., a través del protocolo estándar $O A I-P M H^{23}$, permi- 
tiendo así disponer, además de los metadatos, de un enlace al depósito para tener acceso al texto completo y así evitar duplicar el trabajo en el registro de datos. Este protocolo estándar también es el responsable de la incorporación de los metadatos en el portal UPCommons desde el resto de repositorios para tener un acceso unificado a todos los materiales disponibles en acceso abierto, así como de hacerlos públicos para que los recolectores y directorios tengan acceso a ellos.

\section{El software libre en los ordenadores de las BUPC}

Tal y como se ha comentado antes, también se ha experimentado en aplicaciones locales o de escritorio. La más interesante fue la creación e implantación de imágenes (ver definición $)^{24}$ basadas en Linux $^{25}$ para los ordenadores denominados $P U B$, que se encuentran en las 13 bibliotecas de la $U P C$ y son utilizados por los usuarios para consultar el catálogo e internet. Inicialmente funcionaban con imágenes basadas en sistemas operativos Windows, lo que generaba dos grandes problemas para el personal técnico de las bibliotecas.

\subsection{Problemática inicial}

El primer y gran inconveniente estaba relacionado con mantener actualizada la imagen ya que, como se sabe, un sistema Windows consume muchos recursos, y más a cada nueva versión, lo que requiere ordenadores más y más potentes. Esto planteaba un dilema a las bibliotecas: o bien invertían parte del presupuesto en renovar cada cierto tiempo estos ordenadores, pudiendo tener así un sistema y unas aplicaciones actualizadas y funcionando con un rendimiento aceptable para el usuario, o bien no invertían y continuaban con los mismos ordenadores, pero con un sistema y unas aplicaciones desactualizadas e incluso obsoletas. Por desgracia, este último caso era lo más común, ya que a menudo la inversión requerida era demasiado grande para la biblioteca.

Esto, como es fácil deducir, generaba problemas tanto de seguridad como de incompatibilidad. Se daban muchos casos de usuarios que intentaban abrir documentos realizados con una versión más actual que la aplicación disponible en la imagen, con el resultado de que no se visualizaba o lo hacía incorrectamente. Esto generaba insatisfacción y obligaba a la biblioteca a buscar rápidamente una alternativa, como la de dejar abrir al usuario su documento en un ordenador del propio personal. Por otro lado, también daba lugar a agujeros de seguridad, lo que nos lleva al segundo gran problema.

\section{"El software libre se basa en la existencia de estándares abiertos"}

Dejando de lado el debate de si los sistemas Windows son seguros o no, la cuestión de la seguridad en estos ordenadores $P U B$ se dividía en dos frentes. Por un lado, al tener muchas veces un sistema en una versión anterior hacía que los ordenadores fueran más vulnerables a los nuevos virus, poniendo en riesgo al propio ordenador y a los datos de los usuarios. Esto implicaba que el personal técnico tenía que asegurarse que tanto el sistema como el antivirus estuvieran actualizados y también obligaba a revisarlos periódicamente en busca de virus o fallos de seguridad. Por otro lado, a veces y por la misma razón, era propiamente un usuario malintencionado el que, con un poco de esfuerzo, conseguía vulnerar la seguridad y provocar fallos en el funcionamiento del sistema. Todo esto unido a que un sistema Windows de por sí requiere cada cierto tiempo una reinstalación para un correcto y eficaz funcionamiento, provocaba que el personal tuviera que reinstalar la imagen muy a menudo, dejando al ordenador fuera de servicio durante un tiempo, a veces horas. Esto reducía su disponibilidad y provocaba ofrecer un peor servicio al usuario.

\subsection{Migración a Linux}

Por todos estos motivos y dado que en el entorno de la UPC cada vez hay una tendencia mayor a usar software libre y se conocían otras experiencias de migración a Linux de ordenadores de consulta como en el caso de las bibliotecas de la Universidad Autónoma de Barcelona, se decidió probar la alternativa de crear una imagen en Linux, concretamente una primera versión basada en la distribución Debian ${ }^{26}$ y una segunda en $U_{b u n t u^{27}}$, que es la que actualmente se usa.

Esta nueva imagen es mucho más ligera, permitiendo su uso en ordenadores más antiguos con un rendimiento más que aceptable, lo que reduce considerablemente la inversión que se realiza en la adquisición de máquinas nuevas. También se puede decir que es más robusta y segura ya que, en el año y medio que lleva funcionando, no se ha detectado ningún problema de seguridad. Esto hace que en muy pocos casos se haya tenido que reinstalar, con lo que aumenta la disponibilidad de los ordenadores y mejora el servicio. Asimismo, incorpora herramientas de administración remota que permiten cambiar fácilmente el sistema sin tener que ir físicamente a cada una de las máquinas $\mathrm{y}$ de forma transparente al usuario. En conjunto, todo ello ha reducido el tiempo que el personal de las bibliotecas debe emplear en estos ordenadores, permitiendo invertirlo en otras tareas y en la realización de nuevos proyectos.

Es cierto que se ha mejorado en muchos aspectos, pero debe reconocerse que no todo han sido venta- 
jas. A pesar de que Linux soporta la mayoría de dispositivos y cada día que pasa mejora, todavía existe incompatibilidad con ciertas tarjetas o periféricos, principalmente debido a que las empresas fabricantes todavía no apoyan firmemente al software libre. Concretamente se encontraron problemas con ciertas memorias $U S B$, sobre todo en la primera imagen Debian, con varias impresoras y con algunas placas base y ciertas tarjetas gráficas, que todavía no eran soportadas en las versiones Linux que se usaron. En el caso de las memorias se tuvo que optar por dejar al usuario usar un ordenador del personal con sistema Windows para que pudiera acceder a ellas y se enviara los documentos vía correo electrónico. Gracias a la actualización de la imagen en su versión con Ubuntu, este problema parece haberse solucionado y raramente se encuentran dispositivos de este tipo incompatibles con el sistema.

Para el caso de las impresoras la solución no fue tan fácil, ya que a pesar de que la empresa fabricante sí proporcionaba controladores de sus máquinas para Linux, éstos no tenían las mismas funcionalidades que los equivalentes en Windows. Ello obligó a tener que montar un sistema complementario al controlador del fabricante que las añadiera. Obviamente, a pesar del trabajo que comportó, esto fue posible gracias a que se pudo modificar parte del código del gestor de impresión, cosa que en otros sistemas no habría sido posible. Estos periféricos, a pesar de ciertos fallos puntuales, funcionan a la perfección con este sistema modificado. Por último, se han encontrado algunos casos en que ciertas incompatibilidades con la placa base o con la tarjeta gráfica han provocado problemas, como la no detección del disco duro, un funcionamiento defectuoso del sistema gráfico de las $X$-Windows ${ }^{28}$ o la imposibilidad de hacer funcionar la disquetera o el cd-rom. Normal- mente estos inconvenientes se han solucionado modificando ficheros de configuración del propio Linux. En algún caso se han tenido que actualizar ciertos controladores y aún hay algún caso que está pendiente de ser solucionado.

Otro inconveniente, quizás el más importante que se ha ido encontrando, ha sido el desconocimiento por parte del propio personal y de los usuarios del funcionamiento de un sistema Linux, ya que la mayoría habían utilizado siempre máquinas Windows. Por ello, en las primeras fases de implantación de la nueva imagen se tuvo que invertir mucho tiempo y esfuerzos en la formación del personal y de los usuarios. Carteles, atención personalizada y páginas web fueron algunos de los métodos para ir acercando poco a poco el nuevo sistema a los usuarios. A pesar de que al principio éstos parecían resistirse o, en algún caso, hasta tenerle miedo, cada vez son más los que lo usan con total libertad y agilidad, como cualquier otro sistema. Es cierto que todavía hay usuarios que por comodidad, desconfianza o desconocimiento, siguen prefiriendo usar otros ordenadores de las bibliotecas que todavía tienen sistemas Windows.

\section{Conclusiones}

El software libre está cada vez más presente en las aplicaciones web y de escritorio que se utilizan en las $B U P C$, ya sea por el desarrollo de nuevos proyectos o por la progresiva migración de productos inicialmente llevados a cabo con software propietario.

En general, de la experiencia en las $B U P C$, se puede concluir que el uso y la migración de proyectos a software libre han sido positivos, pero debe indicarse que no es un proceso tan sencillo como a veces se quiere hacer creer. En el caso del uso de aplicaciones web ya creadas, es necesario en muchas ocasiones invertir tiempo en comprender la aplicación antes de poder adaptarla, personalizarla o modificarla para las necesidades requeridas. En el caso de migraciones a software libre, al trabajo que ya supone una migración a veces hay que añadirle el de estudiar qué formato o estándar es el que más conviene y sobre todo, cuál es el que tiene más futuro, para evitar tener que migrar otra vez toda una aplicación si éste desaparece. En el caso de aplicaciones locales o de escritorio, hay que tener en cuenta que, sobre todo al principio, va a ser necesario invertir tiempo en formación y aclimatación de los usuarios, antes de conseguir un sistema estable, robusto y amigable para ellos y para el propio personal de las bibliotecas.

\section{"La migración a software libre ha de ser progresiva para que los usuarios puedan ir asumiendo poco a poco el cambio y descubriendo que el nuevo sistema puede ser tan útil como el anterior"}

También hay que tener en cuenta que la migración a software libre debe ser progresiva, sobre todo en este último ámbito de las aplicaciones de escritorio, ya que en el contexto de la web su uso es casi transparente al usuario. De este modo, todos los usuarios podrán ir asumiendo poco a poco el cambio y descubriendo que el nuevo sistema puede ser tan valioso y útil como el anterior. Es por eso que en las bibliotecas de la $U P C$ aún se conservan ordenadores con sistemas Windows para aquellos usuarios que les cuesta más el cambio y también porque se prefiere ofrecer todas las alternativas para que se pueda escoger aquella que más gusta o conviene. 
A pesar de estos pequeños problemas, las $B U P C$ están plenamente satisfechas con el camino que se ha escogido hacia el software libre, ya que abre un mundo de posibilidades, sobre todo de interoperabilidad, hasta ahora muy difíciles de conseguir con las herramientas propietarias. Esto es muy importante en el ámbito universitario, ya que permitirá interactuar y enlazar con sistemas de otras unidades, y de otras universidades, unificando esfuerzos para crear plataformas más completas para compartir y difundir conocimientos y materiales de una forma mucho más potente de lo que se podría haber pensado hace unos años.

\section{"La apuesta de las BUPC por el software libre está presente en el nuevo plan estratégico Aprèn (2007-2010)"}

La apuesta por el software libre está presente en el nuevo plan estratégico Aprèn ${ }^{29}$, donde se contempla la elaboración de una nueva versión de Bibliotècnica, la biblioteca digital de la $U P C^{30}$ en software libre, que ya está en progreso. A nivel técnico se pretende migrar progresivamente la plataforma a $P H P$ utilizando un gestor de base de datos libre como MySQL o PostgreSQL ${ }^{31}$ $\mathrm{y}$ adaptando si es posible una herramienta de gestión de contenido $(C M S)$ en software libre para facilitar su mantenimiento.

Por último, las $B U P C$ animan a, como mínimo, probar esta alternativa y las posibilidades que ofrece, así como a valorar los beneficios que puede reportar una migración. Las $B U P C$ continuarán con su la- bor, ya que se considera que ofrece muchas ventajas y su filosofía se complementa perfectamente con la de las bibliotecas y las universidades, que es difundir el conocimiento sin barreras ni límites.

\section{Notas}

1. Wikipedia.

http://es.wikipedia.org/wiki/Conocimiento_libre

2. Ley de propiedad intelectual.

http://civil.udg.es/normacivil/estatal/reals/Lpi. html

3. GNU.

http://www.es.gnu.org

4. Free Software Foundation.

http://www.fsf.org

5. GPL.

http://www.opensource.org/licenses/gpl-license. php

6. IRIS-libre.

https://forja.rediris.es/plugins/wiki/index.php?O ficinasDeSoftwareLibre \&id $=205 \&$ type $=g$

\section{RedIris.}

http://www.rediris.es/rediris

8. MediaWiki.

http://www.mediawiki.org

9. Wordpress.

http://wordpress.org

10. LDAP.

http://es.wikipedia.org/wiki/LDAP

\section{DSpace}

http://www.dspace.org

\section{E-prints UPC.}

http://upcommons.upc.edu/e-prints

13. Revistes i Congressos UPC.

http://upcommons.upc.edu/revistes

14. Treballs Acadèmics UPC.

http://upcommons.upc.edu/pfc

15. UPCommons.

http://upcommons.upc.edu

16. GUDE.

http://sod.upc.es/gude

17. PHP.

http://www.php.net

18. MySQL.

http://www.mysql.com

19. Dipòsit de Materials Docents UPC.

http://e-md.upc.edu

20. Atenea: el campus virtual de la $U P C$ http://atenea.upc.edu

21. Moodle.

http://moodle.org

22. SOAP.

http://www.w3.org/TR/soap
23. OAI-PMH.

http://www.openarchives.org

24. Imagen: archivo en el que figura toda la información del ordenador. Se usa como "molde" para configurar nuevos ordenadores sin tener que realizar todos los procesos de instalación de un sistema nuevo. A la vez sirve como copia de seguridad de los datos de ese ordenador antes de realizar alguna operación sobre él.

25. Linux.

http://www.linux.org

26. Debian.

http://www.debian.org

27. Ubuntu.

http://www.ubuntu.com

28. X-Windows.

http://www.x.org

29. Plan estratégico Aprèn de las BUPC. http://bibliotecnica.upc.edu/Pla_estrategic/ apren2010.pdf

30. Bibliotècnica, la biblioteca digital de la UPC.

http://bibliotecnica.upc.edu

31. PostgreSQL.

http://www.postgresql.org

\section{Bibliografía}

Borràs, Antoni; Carreño, Juan; Jorba, Ferran; Prats, Jordi; Ros, Ramon. "Programari de codi lliure per gestionar dipòsits digitals: el procés de tria dut a terme al CBUC". En: BiD: textos universitaris de biblioteconomia i documentació, 2006, n. 16. Consultado en: 04-11-07. http://www2.ub.edu/bid/consulta_articulos. php? fichero=16borras. $h$ tm

De la Vega, Ricard, et al. "Dipòsits col-lectius d'e-informació". En: V Jornades de programari lliure, 2006. Consultado en: 04-11-07.

http://portal.jornadespl.org/ponencies/htm

Prats, Jordi; Prieto, Toni; Rico, Oriol. "UPCommons: portal d'accés obert al coneixement de la UPC'. En: V Jornades de programari lliure, 2006. Consultado en: 04-11-07.

http://portal.jornadespl.org/ponencies/upc-commons-portal-d-acces-obert-al-coneixementdela-upcl

Jorba, Ferran. "Els kiosks Linux a les biblioteques UAB”. En: II Jornades de programari lliure, 2003. Consultado en 04-11-07.

http://www.jornadespl.org/biblioteca/ii-jornades/ponencies/fjorba-2003.pdf

Javier Clavero, Eulàlia Formentí, Toni Prieto, Universitat Politècnica de Catalunya.

javier.clavero@upc.edu eulalia.formenti@upc.edu antonio.juan.prieto@upc.edu 